\title{
Renal artery revascularisation: can we predict who benefits?
}

\author{
Abhizith Deoker, Debabrata Mukherjee
}

Atherosclerotic renal artery stenosis (ARAS) is commonly seen in individuals with vascular disease in other territories, that is, coronary and cerebrovascular disease. ${ }^{1}$ Epidemiological data suggest that ARAS is present in $\sim 7 \%$ of patients over the age of 65 years and in more than half of the patients with evidence of atherosclerosis elsewhere such as abdominal aortic aneurysm, peripheral vascular disease and multivessel coronary artery disease.

The overall goals of therapy in ARAS is normalisation of blood pressure, improvement of renal function, and reduction of the risk of cardiovascular and cerebrovascular events. Among those with existing cardiovascular disease, an important objective is reduction of future adverse events. Optimal management of individuals with ARAS should include lifestyle and pharmacological modification of cardiovascular risk factors, including blood pressure control with effective drugs, evidence-based use of antiplatelet therapy and statins. The important question for clinicians then becomes which individuals are likely to have incremental benefit from renal artery revascularisation beyond such therapies.

In this issue of the journal, Nakajima et $a l^{2}$ attempt to identify clinical and echocardiographic factors associated with improvements of cardiac symptoms after renal artery stenting. Since the initial description of renal artery stenting, there have been multiple contrasting studies on the benefits of renal artery revascularisation. In general, retrospective, and uncontrolled studies have suggested benefit, while rigorous randomised studies have shown a lack of efficacy. The prospective Cardiovascular Outcomes in Renal Atherosclerotic Lesions Study compared the effect of optimal medical therapy alone to stenting with optimal medical therapy, on cardiovascular or renal death, myocardial infarction, hospitalisation for congestive heart failure, stroke, doubling of

Department of Internal Medicine, Texas Tech University Health Science Center, El Paso, Texas, USA

Correspondence to Dr Debabrata Mukherjee, Department of Internal Medicine Texas Tech University Health Science Center, El Paso, Texas 79905, USA; debabrata.mukherjee@ttuhsc.edu serum creatinine level, and need for renal replacement therapy in 947 patients. $^{3}$ In this large trial, renal artery stenting was not associated with a benefit with respect to the prevention of clinical events when added to comprehensive, optimised medical therapy in those with ARAS. ${ }^{3}$ Similarly, the Angioplasty and Stent for Renal Artery Lesions trial of $>800$ patients reported substantial risks but no evidence of a clinical benefit from revascularisation in patients with ARAS. ${ }^{1}$ Since all patients with ARAS do not appear to benefit from renal revascularisation, several parameters have been previously proposed such as the renal artery resistance index, ${ }^{4}$ renal size, and renal vein renin measurement to target potential individuals who may benefit from renal artery revascularisation, but such indices have not shown consistent and good predictive ability. Due to the lack of a consistent benefit, the number of renal artery stenting procedures performed have shown some decline globally but still several thousand procedures are done annually. ${ }^{1}$ It therefore would be logical to try and target the patient cohort most likely to benefit from renal artery stenting. To this end, Nakajima et al, ${ }^{2}$ propose that the echocardiographic index of interventricular septal wall thickness (IVS) was an independent predicator for improvement of cardiac symptoms after renal artery stenting. They hope that this knowledge might increase awareness of the importance of cardiac function assessment in the management of atherosclerotic renal artery disease and may possibly help target appropriate candidates for revascularisation. ${ }^{2}$ Along these lines, Rzeznik et al had previously reported that renal revascularisation is associated with a significant left ventricle (LV) mass reduction during 12-month follow-up. ${ }^{5} \quad$ Furthermore, LV mass was identified as an independent predictor of cardiovascular events following revascularisation procedure. However, there was no improvement of LV diastolic function after revascularisation in their study. ${ }^{5} \mathrm{~A}$ few points need to be understood to better understand the clinical implications of the study findings reported by Nakajima et al. ${ }^{2}$ First, this retrospective registry enrolled patients with de novo ARAS who underwent renal artery stenting for the control of heart failure, angina or both, and the results may not be applicable to those without these symptoms. Second, the primary end point was achieving a lower New York Heart Association (NYHA) functional class and being free from rehospitalisation for heart failure, angina or both, and these end points have a subjective component. Finally, echocardiogram data might have varied among hospitals and assessment was not performed by a blinded imaging core laboratory. Furthermore, the presence of greater LV mass, represented by IVS in this study is expectedly predictive of future cardiovascular events, despite the potential of some regression with blood pressure (BP) improvement following renal artery stenting. This may be because of advanced structural changes, for example, fibrosis which is a frequent feature of LV hypertrophy. ${ }^{6}$ Non-invasive detection of fibrosis applying contrast-enhanced cardiac magnetic resonance and late gadolinium enhancement in different forms of LV hypertrophy suggests that remodelling may not be entirely reversible despite BP improvement. It is likely among the non-responders that there was greater IVS thickness and LV mass, and worse diastolic function since E velocity was higher, suggesting more elevated LA pressures. Based on these limitations, the findings of this study should be considered hypothesis-generating and need validation in an appropriately designed prospective randomised trial. Until then, we should follow national guidelines (table 1) in the decision-making process for renal artery revascularisation with a multidisciplinary team approach for the individual patient weighing in risks versus benefits. $^{7-9}$ At this time, ARAS with unexplained pulmonary oedema and/or recurrent heart failure are the only class I guideline-based recommendations for renal artery revascularisation.

Overall, based on totality of data, it appears that only a subset of patients with ARAS are likely to benefit from renal artery stenting and identification of this cohort is paramount to achieving longterm benefits from renal artery revascularisation. Future prospective studies will-help determine if IVS will truly turn out to be the 'holy grail' in determining candidacy for renal revascularisation, but at this time, it seems prudent to select patients carefully for renal revascularisation based on objective evidence of renal ischaemia without evidence of significant parenchymal renal disease or nephropathy. ${ }^{1}$ The current ACC/ AHA guidelines are a reasonable reference point for which patients to assess 


\section{Editorial}

Table 1 National guidelines for renal artery revascularisation in patients with cardiovascular symptoms

\begin{tabular}{ll}
\hline Society & Recommendations \\
\hline $\begin{array}{l}\text { American College of Cardiology Foundation/American Heart Association Task Force on } \\
\text { Practice Guidelines }^{7}\end{array}$ & $\begin{array}{l}\text { Class I: Percutaneous revascularisation is indicated for patients with haemodynamically } \\
\text { significant RAS and recurrent, unexplained congestive heart failure or sudden, } \\
\text { unexplained pulmonary oedema. }\end{array}$ \\
$\begin{array}{ll}\text { Class Ila: Percutaneous revascularisation is reasonable for patients with } \\
\text { haemodynamically significant RAS and unstable angina. }\end{array}$ \\
$\begin{array}{ll}\text { European Society of Cardiology (ESC) } \\
\text { Class Ilb: Treatment of RAS, by balloon angioplasty with or without stenting, may be } \\
\text { considered for patients with RAS and unexplained recurrent congestive heart failure or } \\
\text { sudden pulmonary oedema and preserved systolic left ventricular function. }\end{array}$ \\
$\begin{array}{l}\text { Appropriate } \\
\text { Cardiac disturbance syndromes (flash pulmonary oedema or acute coronary syndrome } \\
\text { (ACS)) with severe hypertension (appropriate) } \\
\text { Resistant HTN (uncontrolled hypertension with failure of maximally tolerated doses } \\
\text { of at least three antihypertensive agents, one of which is a diuretic, or intolerance to } \\
\text { medications) } \\
\text { May be appropriate } \\
\text { Unilateral RAS with prior episodes of congestive heart failure } \\
\text { Rarely appropriate care } \\
\text { Unilateral, solitary or bilateral RAS with controlled BP and normal renal function }\end{array}$ \\
\hline
\end{tabular}

RAS, Renal artery stenosis; HTN, Hypertension.

for ARAS and identify those likely to benefit from revascularisation. As stated earlier, it is imperative that these patients receive optimal secondary preventative therapy including antiplatelet therapies, high intensity statins, renin-angiotensin blockers and other appropriate drugs as indicated for the individual patient to reduce future cardiovascular events. ${ }^{10}$ At this time, given the lack of benefit in most cases, clinicians should be quite selective before proceeding with renal artery stenting.

Contributors AD drafted the initial article, contributed to the critical revision of the draft and gave final approval of the version to be published. DM conceived and designed the article, critically revised the draft and gave final approval of the version to be published.

\section{Competing interests None declared.}

Provenance and peer review Commissioned; internally peer reviewed.

(C) Article author(s) (or their employer(s) unless otherwise stated in the text of the article) 2017. All rights reserved. No commercial use is permitted unless otherwise expressly granted.

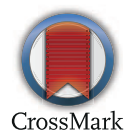

To cite Deoker A, Mukherjee D. Heart Asia 2017;9:12.. doi:10.1136/heartasia-2017-010951

\section{CLinked}

- http://dx.doi.org/10.1136/heartasia-2017-010934

Heart Asia 2017;9:1-2. doi:10.1136/

heartasia-2017-010951

\section{REFERENCES}

1 Mukherjee D. Renal artery revascularization: is there a rationale to perform? JACC Cardiovasc Interv 2009;2:183-4.

2. Nakajima Y, Kawarada O, Higashimori A, et al. Predictors of cardiac benefits of renal artery stenting: a multicenter retrospective registry (PREMIERE Registry). Heart Asia 2017

3 Cooper CJ, Murphy TP, Cutlip DE, et al. Stenting and medical therapy for atherosclerotic renal-artery stenosis. N Eng/ J Med 2014;370:13-22.

4 Mukherjee D, Bhatt DL, Robbins M, et al. Renal artery end-diastolic velocity and renal artery resistance index as predictors of outcome after renal stenting. Am J Cardiol 2001;88:1064-6.

5 Rzeznik D, Przewlocki T, Kablak-Ziembicka A, et al. Effect of renal artery revascularization on left ventricular hypertrophy, diastolic function, blood pressure, and the one-year outcome. J Vasc Surg 2011:53:692-7.

6 Rudolph A, Abdel-Aty H, Bohl S, et al. Noninvasive detection of fibrosis applying contrast-enhanced cardiac magnetic resonance in different forms of left ventricular hypertrophy relation to remodeling. J Am Coll Cardiol 2009:53:284-91.

7 Anderson JL, Halperin JL, Albert NM, et al. Management of patients with peripheral artery disease (compilation of 2005 and 2011 ACCF/AHA guideline recommendations): a report of the American college of cardiology foundation/American heart association task force on practice guidelines. Circulation 2013;127:1425-43.

8 Tendera M, Aboyans V, Bartelink ML, et al. ESC Guidelines on the diagnosis and treatment of peripheral artery diseases: document covering atherosclerotic disease of extracranial carotid and vertebral, mesenteric, renal, upper and lower extremity arteries: the task force on the diagnosis and treatment of peripheral artery diseases of the european society of cardiology (ESC). Eur Heart J 2011:32:2851-906

9 Parikh SA, Shishehbor MH, Gray BH, et al. SCAI expert consensus statement for renal artery stenting appropriate use. Catheter Cardiovasc Interv 2014;84:1163-71.

10 Mukherjee D, Lingam P, Chetcuti S, et al. Missed opportunities to treat atherosclerosis in patients undergoing peripheral vascular interventions: insights from the University of Michigan Peripheral Vascular Disease Quality Improvement Initiative (PVD-QI2). Circulation

2002;106:1909-12. 